\title{
Treatment with CA-074Me, a Cathepsin B inhibitor, reduces lung interstitial inflammation and fibrosis in a rat model of polymyositis
}

\author{
Li Zhang ${ }^{1,9}$, Xiao-Hong Fu ${ }^{2,9}$, Yong $\mathrm{Yu}^{3}$, Ruo-Hong Shui ${ }^{4}$, Chun $\mathrm{Li}^{5}$, Hai-Ying Zeng ${ }^{6}$, Yu-Lei Qiao ${ }^{7}$, Li-Yan $\mathrm{Ni}^{8}$ and \\ Qiang Wang ${ }^{1}$
}

Cathepsin $B(C B)$ is involved in the turnover of proteins and has various roles in maintaining the normal metabolism of cells. In our recent study, CB is increased in the muscles of polymyositis/dermatomyositis (PM/DM). However, the role of $C B$ in interstitial lung disease (ILD) has not been reported. ILD is a frequent complication of PM/DM, which is the leading cause of death in PM/DM. It carries high morbidity and mortality in connective tissue diseases, characterized by an overproduction of inflammatory cytokines and induced fibrosis, resulting in respiratory failure. The etiology and pathogenesis of ILD remain incompletely understood. This study investigated whether treatment with CA-074Me, a specific inhibitor of $C B$, attenuates ILD in PM. CB expression, inflammation, and fibrosis were analyzed in the lung tissues from patients with PM/DM. The animal model of PM was induced in guinea pigs with Coxsackie virus B1 (CVB1).

CA-074Me was given $24 \mathrm{~h}$ after CVB1 injection for 7 consecutive days. At the end of the experiment, the animals were killed and lung tissues were collected for the following analysis. Inflammation, fibrosis and apoptosis cells, and cytokines were assessed by histological examinations and immunohistochemical analyses, western blot analysis and transferasemediated dUTP nick-end labeling assay. In patients with PM/DM, the protein levels of CB were significantly elevated in lung tissues compared with healthy controls, which correlated with increases in inflammation and fibrosis. Similarly, the expression of $\mathrm{CB}$, inflammation and fibrosis, $\mathrm{CD} 8^{+} \mathrm{T}_{\text {cell, }} \mathrm{CD} 68^{+}$cell, tumor necrosis factor-alpha, transforming growth factor-beta1 infiltrations, and apoptotic cell death were significantly increased in lung tissues of the guinea-pig model of CVB1-induced PM. These changes were attenuated by the administration of CA-074Me. In conclusion, this study demonstrates that PM/DM increases CB expression in lung tissues and inhibition of CB reduces ILD in a guinea-pig model of CVB1-induced PM. This finding suggests that CB may be a potential therapeutic target for ILD.

Laboratory Investigation (2015) 95, 65-77; doi:10.1038/labinvest.2014.135; published online 10 November 2014

Polymyositis/dermatomyositis (PM/DM) presents with a varying degree of muscle weakness that develops slowly, over weeks to months, but acutely in rare cases. ${ }^{1}$ About $19.9-75 \%$ of patients with $\mathrm{PM} / \mathrm{DM}$ develop interstitial lung disease (ILD). ${ }^{2}$ It is the leading cause of death in PM/DM, and carries high morbidity and mortality in connective tissue diseases (CTDs). ILD includes a heterogeneous group of disorders that result in diffuse parenchymal lung disease, with overlapping clinical, radiographic, and physiologic manifestations. It's well known that ILD leads to more severe pulmonary fibrosis and pulmonary hypertension, and even respiratory failure to death. In some patients, there occurs fatally unpredictable acute attacks without effective control measures. ${ }^{3,4}$ ILD is a severe inflammatory condition resulting from the PM/DM with the overproduction of inflammatory cytokines by immune cells, leading to fibrosis. The etiology and pathogenesis of ILD remain incompletely understood. A complex network consisting of cytokines, chemical mediators, growth factors, and oxygen radicals derived from inflammatory cells closely controls the progression of

\footnotetext{
${ }^{1}$ Department of Dermatology, Zhongshan Hospital, Fudan University, Shanghai, PR China; ${ }^{2}$ Department of Ultrasound, Shanghai Pudong Gongli Hospital, Shanghai, PR China; ${ }^{3}$ Key Laboratory of Viral Heart Diseases, Ministry of Public Health, Shanghai Institute of Cardiovascular Diseases, Zhongshan Hospital, Fudan University, Shanghai, PR China; ${ }^{4}$ Department of Pathology, Tumor Hospital, Fudan University, Shanghai, PR China; ${ }^{5}$ Department of Pulmonary Medicine, Zhongshan Hospital, Fudan University, Shanghai, PR China; ${ }^{6}$ Department of Pathology, Zhongshan Hospital, Fudan University, Shanghai, PR China; ${ }^{7}$ Department of thoracic surgery, Zhongshan Hospital, Fudan University, Shanghai, PR China and ${ }^{8}$ Department of Dermatology, Shanghai Skin Diseases Hospital, Shanghai, PR China

Correspondence: Dr Q Wang, MD, Department of Dermatology, Zhongshan Hospital, Fudan University, 180 Fenglin Road, Xuhui District, Shanghai 200032, PR China. E-mail: wang.qiang@zs-hospital.sh.cn

${ }^{9}$ These authors contributed equally to this work.

Received 19 July 2014; revised 27 September 2014; accepted 1 October 2014
} 
fibrosis. Some insights of understanding the course of pulmonary fibrosis have come from greater number of $\mathrm{CD}^{+}{ }^{+} \mathrm{T}$ cells ${ }^{5}$ and $\mathrm{CD}_{68}{ }^{+}$macrophages. ${ }^{6}$ Pro-inflammatory cytokine expression (especially tumor necrosis factor-alpha; TNF- $\alpha$ ) participates in silica-induced lung fibrosis. ${ }^{7}$ So far, there is no specific therapy available for ILD associated with CTD. Corticosteroids have revolutionized the treatment of several chronic inflammatory diseases including autoimmune and genetic muscle diseases. However, despite their therapeutic benefits, their use is limited owing to significant side effects, including steroid induced myopathy, fat deposition, adrenal deficiency, hyperglycemia, and osteoporosis. Biological treatments $^{8-10}$ are considered to be another potential successful therapy to control ILD. Infliximab, adalimumab, golimumab, and certolizumab (the soluble TNF receptor etanercept and the anti-TNF monoclonal antibodies); anakinra (the IL-1 receptor antagonist); tocilizumab (the anti-IL-6 receptor monoclonal antibody) as well as Rituximab, CTLA-4-Ig (the anti-T-cell agent abatacept) have been used to treat CTDs-ILD. However, they all cause severe side effects, which significantly limit their use in clinical settings. Therefore, it is necessary to develop novel and effective therapies for ILD.

Cathepsin B (CB) is a papain-family cysteine protease, normally located in lysosomes. CB is involved in the turnover of proteins and has various roles in maintaining the normal metabolism of cells. CB is an important molecule involved in autophagy ${ }^{11}$ and under normal conditions, it has an important role in the maintenance of physiological function and also acts as a scavenger. ${ }^{12} \mathrm{CB}$ is also known to activate promatrix metalloproteinases, which in turn, target the extracellular matrix (ECM), thereby inducing ECM degradation and facilitating cell migration. This protease has been implicated in pathological conditions, eg, tumor progression and arthritis. In disease conditions, increases in the expression of $\mathrm{CB}$ occur at both the gene and protein levels. Overexpression of $\mathrm{CB}$ has been observed in various malignancies, including the brain, ${ }^{13}$ lung, ${ }^{14}$ prostate, ${ }^{15}$ etc. Our recent study has found that $\mathrm{CB}$ was elevated in the muscle tissues from the guinea-pig model of PM induced by Coxsackie virus B1 (CVB1) and patients with PM, and inhibition of $\mathrm{CB}$ reduced infiltration of inflammatory cells and apoptosis in an animal model of PM. ${ }^{16}$ However, it remains to be determined whether inhibition of $\mathrm{CB}$ will provide similar protective effects in the lung tissue in PM.

CA-074Me is a methylative epoxy chlorine succinylcholine $\mathrm{N}$-(L-3-trans-propyl-carbamoyloxirane-2-carbonyl)-L-isoleucyl-L-proline methyl ester as a specific inhibitor of CB. $\mathrm{CA}-074 \mathrm{Me}$ is a membrane-permanent pro-inhibitor, which, after internalization and conversion to CA-074, inactivates intracellular CB. ${ }^{17} \mathrm{CA}-074 \mathrm{Me}$ showed good therapeutic effect on tumor, viral myocarditis, and other diseases. ${ }^{18}$ Thus, in this study, we determined the expression of $\mathrm{CB}$ in lung tissues from patients with PM and a guinea-pig model of PM, and investigated the effects of CA-074Me on inflammation and fibrosis in PM-associated ILD.

\section{MATERIALS AND METHODS \\ Patients of PM/DM}

Thirteen patients with PM (six) and DM (seven) were recruited. They had been consecutively admitted to our hospital and were diagnosed as PM/DM according to the criteria proposed by Bohan and Peter. ${ }^{19,20}$ Clinical profiles of the patients are summarized in Table 1 . All patients were considered to have active disease based on the muscle weakness, the serum-elevated creatine kinase (CK), and/or abnormal electromyography (EMG) without or with skin rash (in all DM patients). Lung tissues biopsy specimens were obtained from all $13 \mathrm{PM} / \mathrm{DM}$ patients by fiberoptic bronchoscopy examination. Normal human lung samples were collected from patients who had partial lung resection, including tumor and ground glass opacity, and were histologically confirmed. Informed consents were obtained from all patients. The study protocol was approved by the Zhongshan Hospital research ethics committee.

\section{Animal Studies}

Thirty-two female shorthair guinea pigs (body weight: $154 \pm 18 \mathrm{~g}$ and age: 4 weeks old) were purchased from animal center of Zhongshan Hospital of Fudan University (Shanghai, China) under the license from the home office in accordance with the Animal (Scientific Procedures) Act 1986 (SYXK 2007-0002). The animal models of PM were established by injection with CVB1 as described previously. ${ }^{16}$ In brief, four experimental groups(each group contains eight guinea pigs) were included: (A) sham group: received normal saline; (B) CVB1 + None group: received CVB1 + Freunds complete adjuvant (FCA); (C) CVB1 + Saline group (pseudo-intervention group): received CVB1 + FCA + normal saline (NS); and (D) CVB1 + CA-074Me group: $\mathrm{CVB} 1+\mathrm{FCA}+\mathrm{CA}-$ 074Me. CA-074Me (Biomol, USA, $4 \mathrm{mg} / \mathrm{kg} /$ day i.m.) was given $24 \mathrm{~h}$ after CVB1 injection for 7 consecutive days. Four weeks after CVB1 injection, the animals were killed, and lung tissues were collected for the following experiments. The animal use protocol was approved by the Institutional Animal Care and Use Committee at the Zhongshan Hospital, Fudan University.

\section{Reagents}

Rabbit anti-rat CB polyclonal antibody (Abcam, USA, Cat No.ab33538), mouse anti-human CD8 antibody (Abcam), mouse anti-human CD4 antibody (Abcam), mouse antihuman CD68 antibody (Abcam), rabbit anti-mouse TNF- $\alpha$ antibody (Bioworld, Cat No. BS1857), Rabbit anti-humantransforming growth factor-betal (TGF- $\beta 1(\mathrm{~V})-\mathrm{sc}-146)$ polyclonal antibody (Santa Cruz Biotechnology) were purchased for IHC and WB. 3,3'-diaminobenzidine (DAB) kit was purchased from Maixin Biological Company (Fuzhou, China), HRP-conjugated monoclonal mouse anti-glyceraldehyde-3-phosphate dehydrogenase (GAPDH) from KangChen Bio-tech (Shanghai, China), Trizol reagent 
Table 1 The clinical profiles of 13 polymyositis/dermatomyositis patients

\begin{tabular}{|c|c|c|c|c|c|c|c|c|c|}
\hline Patient no. & Duration (m) & MW & CK & CK-MM & LDH & EMG & $\mathrm{HRCT}$ & Biopsy of muscule & PFT \\
\hline PM1 & 6 & + & 4188 & 4047 & 910 & + & + & + & + \\
\hline PM3 & 3 & + & 1563 & 1478 & 602 & - & + & + & + \\
\hline PM4 & 2 & + & 247 & 222 & 411 & + & + & + & + \\
\hline PM6 & 2 & + & 2305 & 2239 & 773 & + & + & + & + \\
\hline DM1 & 2 & + & 179 & 163.3 & 500 & - & + & + & - \\
\hline DM2 & 3 & - & 47 & 23 & 383 & ND & + & ND & + \\
\hline DM3 & 4 & + & 651 & 621 & 350 & ND & + & + & ND \\
\hline DM4 & 6 & - & 86 & 62 & 237 & ND & + & ND & ND \\
\hline
\end{tabular}

Abbreviations: -, negative; +, positive; CK, creatine kinase (10-170U/L); CK-MM, creatine kinase MM isoenzyme(10-110U/L); EMG, electromyography; HRCT, high-resolution computed tomography; LDH, lactate dehydrogenase (109-245U/L); m, month; MW, muscle weakness; ND, not done; PFT, pulmonary function test.

from Invitrogen (USA), BCA reagent from TIANGEN BIOTECH (Beijing, China).

CA-074Me was purchased from Biomol (molecular formula is $\mathrm{C}_{19} \mathrm{H}_{31} \mathrm{~N}_{3} \mathrm{O}_{6}$, and molecular weight is $397.5 \mathrm{kDa}$ ).

\section{H \& E Staining}

For microscopic examination, $5-\mu \mathrm{m}$-thick formalin-fixed and paraffin-embedded sections of lung tissues were stained with hematoxylin and eosin (H\&E). Sections were evaluated microscopically. Extension of inflammation was graded into the following four categories: ${ }^{21}$ grade 0 , normal lung tissue without inflammation, scored 0 ; grade 1 ,minimal alveolitis $(+)$, widened alveolar septa due to inflammatory cells infiltration, the lesions confined to $<20 \%$ of the whole lung, scored 1.0; grade 2, moderate alveolitis $(++)$, the lesions extended to $20-50 \%$ of the whole lung, scored 2.0 ; grade 3 , severe alveolitis $(+++)$, diffuse lesions in $>50 \%$ of the whole lung, scored 3.0.

\section{Masson's Trichrome Staining}

For microscopic examination, 5- $\mu \mathrm{m}$-thick formalin-fixed and paraffin-embedded sections of lung tissues were stained with Masson trichrome staining according to standard techniques. Sections were evaluated microscopically.

Extension of fibrosis was scored according to the Ashcroft $\mathrm{T}: 22$ : normal lung; 1: minimal fibrous thickening of alveolar or bronchiolar walls; 2: between 1 and 3; 3: moderate fibrous thickening of walls without obvious damage to lung architecture; 4: between 3 and 5; 5: increased fibrosis with definite damage to the lung structure and formation of fibrous bands or small fibrous masses; 6: between 5 and 7; 7: severe distortion of structure and large fibrous areas; 'honeycomb lung' is placed in this category;8: total fibrous obliteration of the field.

Also, the image was analyzed by Leica Qwin V3 System with collagen fibrils showing green, muscular fiber and red cell showing red, nuclear showing blue.

\section{Immunohistochemical Analyses}

Four $\mu \mathrm{m}$-thick sections were made. Sections were initially deparaffinized by xylene and dehydrated with ethanol. Endogenous peroxidase activity was blocked by $3 \%$ hydrogen peroxide in methanol at room temperature for $15 \mathrm{~min}$, then dipped into ethylenediamine tetraacetic acid to restore antigen. After cooling to room temperature, sections were incubated with the diluted primary antibodies (CB antibody, TNF- $\alpha$ antibody, TGF- $\beta 1(\mathrm{~V})$-sc-146 antibody, CD4 antibody, CD8 antibody and CD68 antibody) (1:100) in a wet box at $4{ }^{\circ} \mathrm{C}$ overnight. The next day, sections were incubated with secondary antibody and EnVision (ChemMafe EnVision ${ }^{+} / \mathrm{HRP}$ ). The reaction was then visualized with a DAB kit. Sections were counterstained with hematoxylin, dehydrated, and evaluated under light microscopy (Nikon, Japan). Lung tissue cells containing yellow granulation in the endochylema or nucleus were considered as positive. The number of positive cells was counted with Q500IW image analysis system (Leica, Germany) and Image-Pro Plus 6.0 software. 
a

d

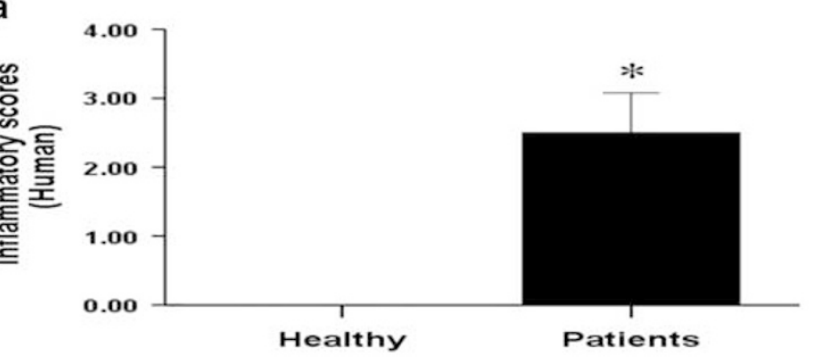

C

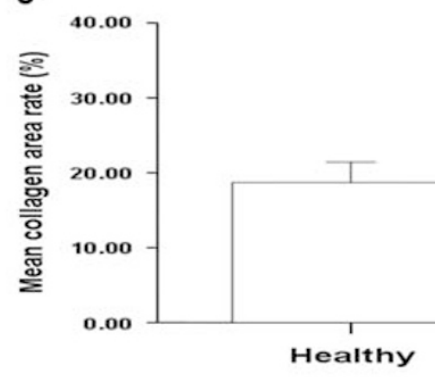

Healthy
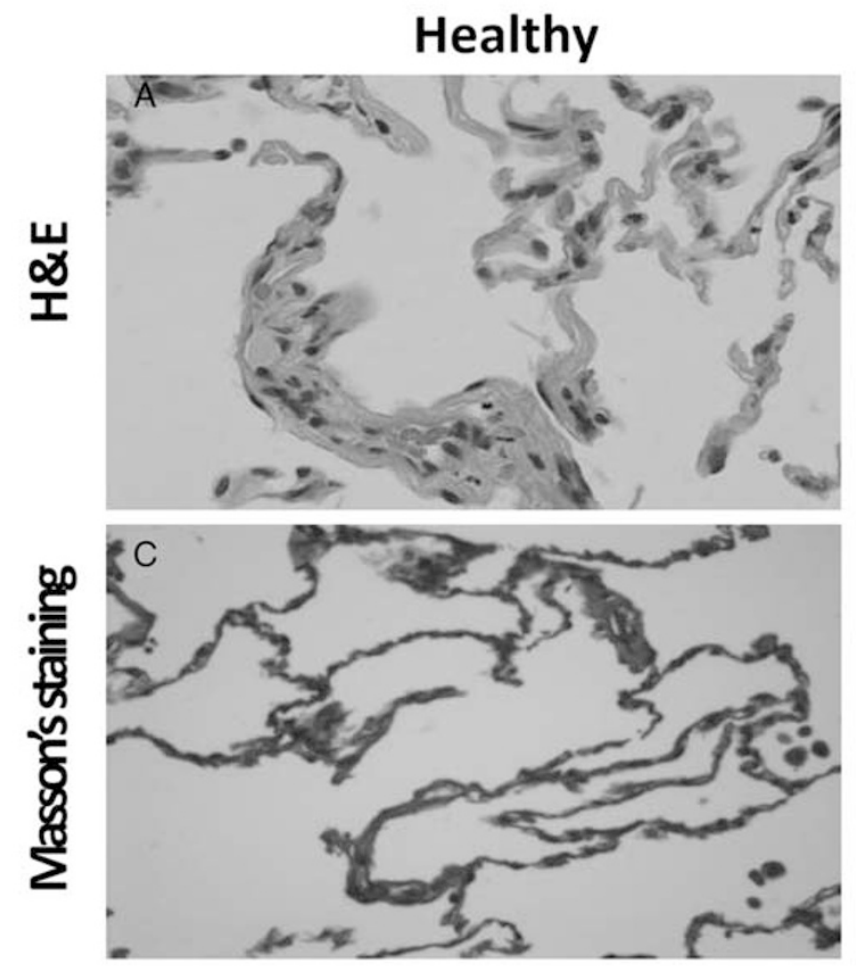

b

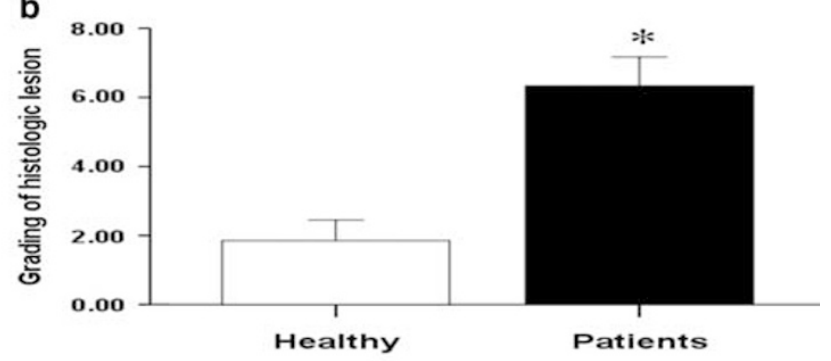

*

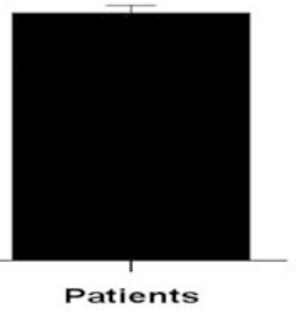

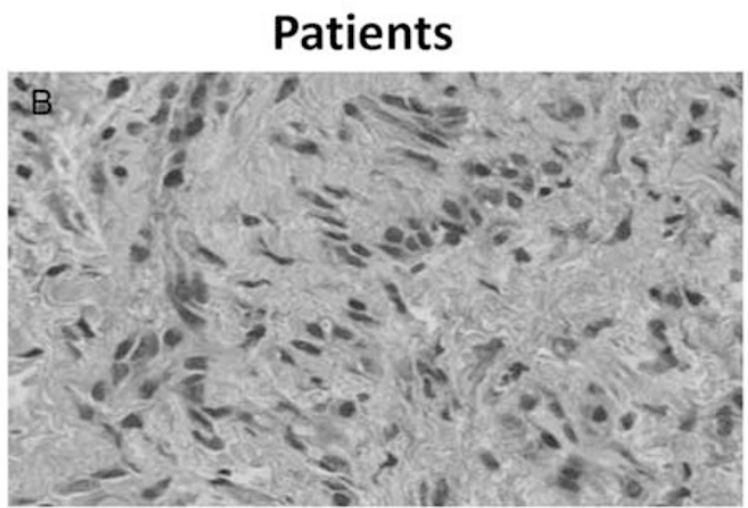

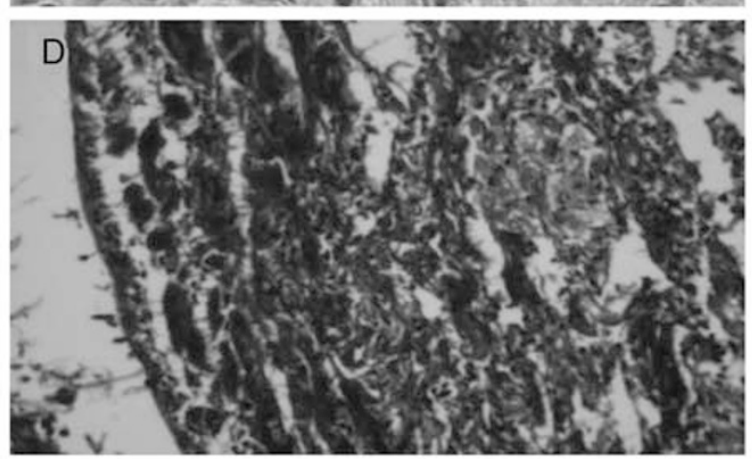

Figure $1 \mathrm{HE}$ and Masson's trichrome staining analyses of inflammation and fibrosis in lung tissues from patients with PM/DM (10 $\times 40)$. (a ,c) $=$ Healthy group $(n=5) ;(\mathbf{b}, \mathbf{d})=$ Patient group $(n=6)$. In PM/DM patients, the inflammatory score was significantly higher (a). The grading of histological lesion (the fibrosis score) in lung tissues in healthy controls was significantly less than that in the patients group (b). The collagen area rate in lung tissues increased in the patients group in comparison with healthy group with significant difference (c). There was no infiltration of inflammatory cells in lung tissues of healthy controls (d-A), but the infiltration of inflammatory cells, widened alveolar septa, and pulmonary interstitial fibrosis in lung tissues were found in PM/DM patients (d-B). The collagen area and degree of fibrosis in lung tissues in healthy controls (d-C) was less observed than that in the patients group (d-D). Data are expressed as means \pm s.d. and compared by Student $t$-test. ${ }^{*} P<0.05$ in comparison with Healthy group.

\section{Terminal Deoxynucleotidyl Transferase-Mediated dUTP Nick-End Labeling (TUNEL) Assays}

The rate of apoptotic cells in lung tissues of animals was quantitated by the TUNEL assay (in situ Apoptosis Detection
Kit, POD, Boehringer Mannheim, Cat. No. 1684795, Germany) according to the manufacturer's instructions. In brief, the deparaffinized sections were incubated with the proteinase $\mathrm{K}$ for $15 \mathrm{~min}$ at room temperature. After washing 
a
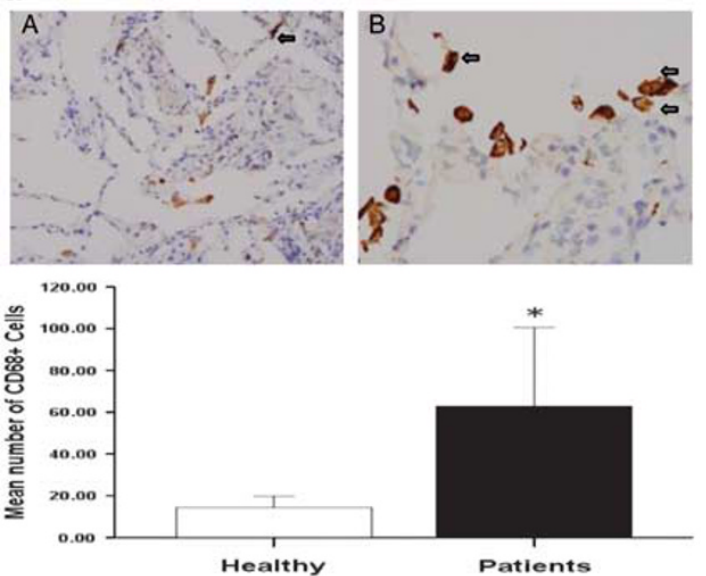

b
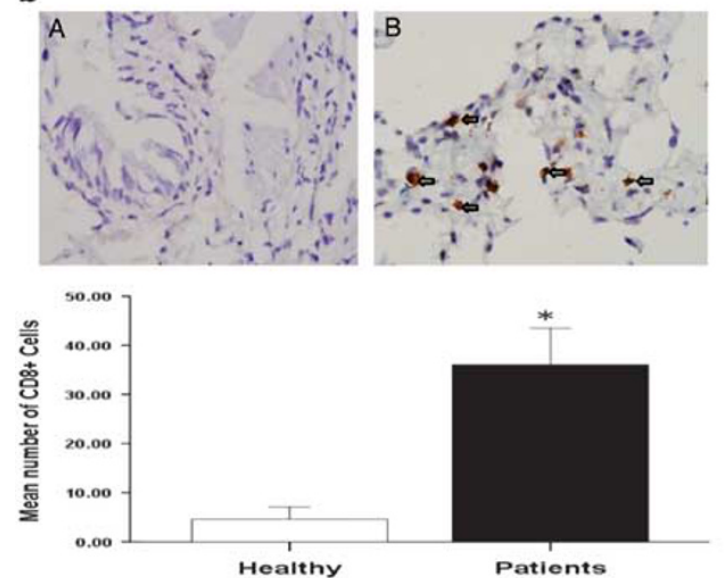

C
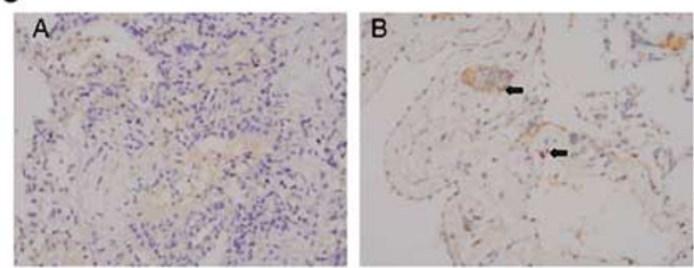

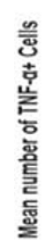

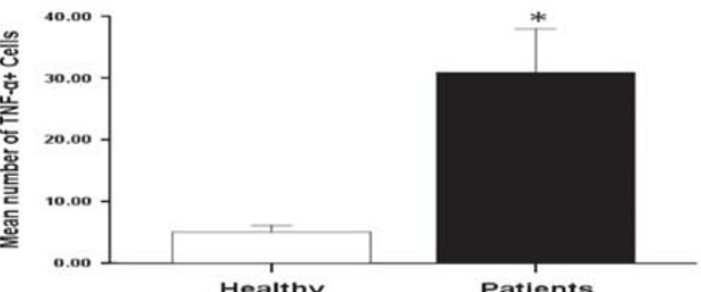

d
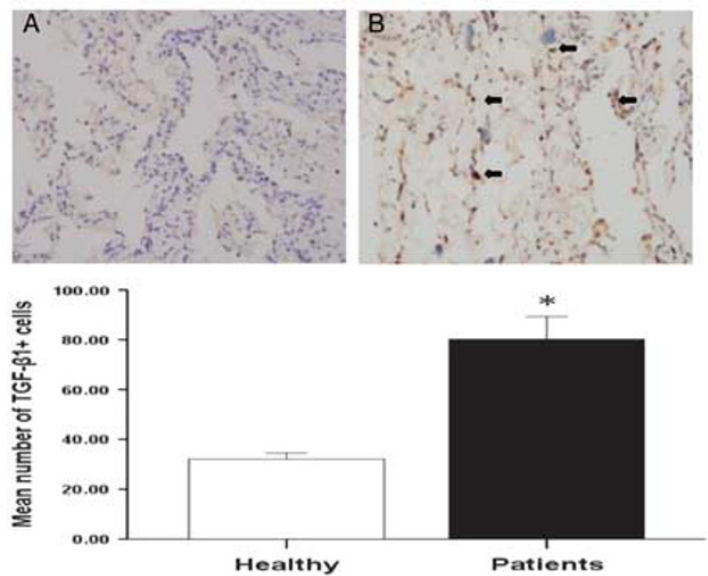

e
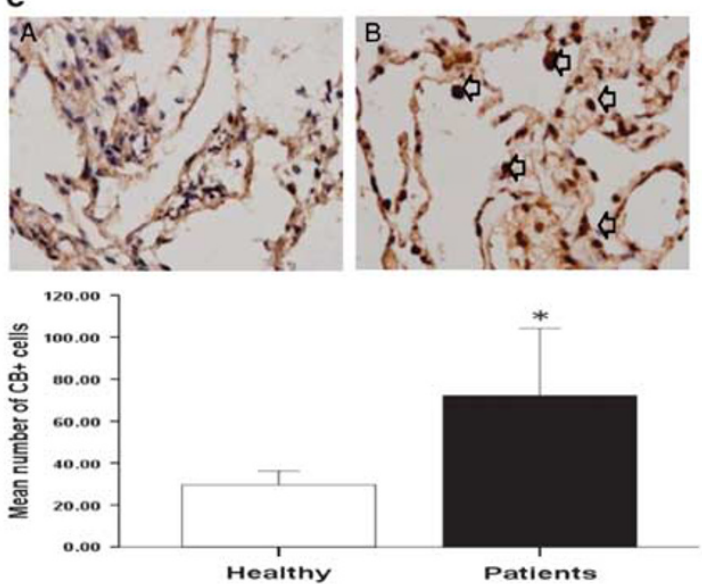

f
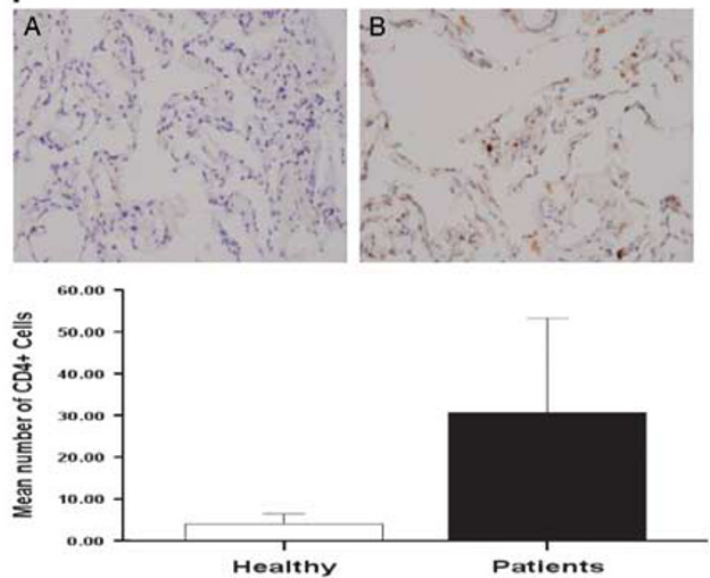

Figure 2 Inflammation, the expression of CB, TNF- $\alpha$, and TGF- $\beta 1$ in lung tissues from human patients with PM/DM $(10 \times 40)$. (a) $=$ Healthy group $(n=5) ;(\mathbf{b})=$ Patient group $(n=6)$. The $\mathrm{CD} 8^{+}$cells (yellow granulation in the cell membrane, arrows showing $\mathrm{CD} 68^{+}$cells) were less seen in lung tissues of healthy controls (a-A) than that in PM/DM patients (a-B). In PM/DM patients, the number of CD68 ${ }^{+}$cells was significantly higher (a). Similarly, CD8 ${ }^{+}$T cells, TNF- $\alpha$-positive cells, TGF- $\beta 1$-positive cells, and CB-positive cells (yellow granulation in the cell membrane, arrows showing the marked cells) were less seen in lung tissues of healthy controls $(\mathbf{b}, \mathbf{c}, \mathbf{d}, \mathbf{e}-\mathrm{A})$ than that in PM/DM patients $(\mathbf{b}, \mathbf{c}, \mathbf{d}, \mathbf{e}-\mathbf{B})$. The CD4 ${ }^{+} \mathrm{T}_{\text {cells }}(\mathrm{yellow}$ granulation in the cell membrane, arrows showing $\mathrm{CD}^{+}{ }^{+} \mathrm{T}$ cells) were similar in lung tissues of healthy controls and PM/DM patients (f). Data are expressed as means \pm s.d. and compared by Student $t$-test. ${ }^{*} P<0.05$ in comparison with Healthy group. 
in PBS Tween-20 for 2 min twice, sections were incubated in $3 \% \mathrm{H}_{2} \mathrm{O}_{2}$ for $10 \mathrm{~min}$ to block endogenous peroxidase activity. After washing with PBS twice, sections were labeled with TdT mixture for $60 \mathrm{~min}$ at $37^{\circ} \mathrm{C}$, and then incubated in $2 \times$ SSC for $15 \mathrm{~min}$ at room temperature. After washing with PBS twice, Avidin-HRP was added. The sections were finally counterstained with hematoxylin. Brown particles in the nucleus were considered (in $\mathrm{DAB}$ as the substrate) as positive signals. Data were expressed as the rate of the number of TUNEL-positive cells per 40 high-power fields (OLYMPUS CX31 biology microscope).

\section{Western Blot Analysis}

Lung tissues were homogenized in western blot analysis buffer. Protein concentration was determined using a BCA kit. Twenty micrograms of protein from each sample was subjected to electrophoresis on $12 \%$ sodium dodecyl sulfate-polyacrylamide gel, and then transferred to polyvinylidenedifluoride (PVDF) membranes on a semidry electrotransferring unit (Bio-Rad, USA). PVDF membranes were blocked with $3 \%$ albumin bovine $\mathrm{V}$ for $2 \mathrm{~h}$ and incubated with the diluted primary antibodies against $\mathrm{CB}$, TNF- $\alpha$, TGF- $\beta 1$ overnight at $4{ }^{\circ} \mathrm{C}$. After the overnight incubation with the primary antibody, membranes were washed by phosphate-buffered saline (with $0.1 \%$ Tween-20) and incubated with HRP-conjugated secondary antibody for $2 \mathrm{~h}$. After extensive washing, blots were detected with enhanced chemiluminescent autoradiography reagent (TIANGEN BIOTECH) according to the manufacturer's instruction. GAPDH, CB, TNF- $\alpha$, TGF- $\beta 1$ were detected at a molecular size of about $38 \mathrm{kDa}, 27 \mathrm{kDa}, 30 \mathrm{kDa}, 39 \mathrm{kDa}$, respectively. The signal intensity was quantitatively analyzed with Quantity-One analysis software.

\section{Statistical Analysis}

Data were means \pm s.d., unless otherwise indicated. The difference among multiple groups $(\geq 3)$ was determined by one-way analysis of variance (ANOVA) followed by Bonferroni. For comparison between two groups, $t$-test was used. A $P$-value of $<0.05$ was considered statistical difference.

\section{RESULTS \\ Characterization of Lung Pathological Changes in Patients with PM/DM}

To determine ILD in PM/DM, we analyzed pathological changes in the lung. H\&E staining revealed scattered and focal distribution of inflammatory cell infiltration, loss of pulmonary epithelial cells, fibrous thickening of alveolar or bronchiolar walls, widened alveolar septa, and even severe distortion of lung structure in lung tissues from PM/DM patients; however, no similar changes were observed in healthy controls (Figures 1a-d).The scores of inflammation in PM patients significantly increased in comparison with the healthy controls $(P<0.01$, Figure 1a). The infiltration of inflammatory cells was further demonstrated by immunohistological staining for $\mathrm{CD}^{+} 8^{+}$cell, $\mathrm{CD} 8^{+} \mathrm{T}$ cell, and $\mathrm{CD} 4^{+} \mathrm{T}$ cell. More $\mathrm{CD} 68^{+}$cells $(P<0.05)$ and $\mathrm{CD} 8^{+} \mathrm{T}$ cells $(P<0.01)$ were found in the lung tissues of patients with PM than those of healthy controls (Figures $2 \mathrm{a}$ and $\mathrm{b}$ ). Yet, $\mathrm{CD} 4^{+} \mathrm{T}$ cells seemed similar between patients and healthy controls $(P>0.05$, Figure 2f).

TNF- $\alpha$ and TGF- $\beta 1$ have been implicated in lung fibrosis. Thus, we analyzed the TNF- $\alpha$ and TGF- $\beta 1$ expression in lung tissues from PM/DM patients and healthy controls by immunohistological chemistry. The number of TNF- $\alpha$ - and TGF- $\beta 1$-positive cells was significantly greater in PM/DM patients than that in the healthy controls $(P<0.01$, respectively. Figures $2 \mathrm{c}$ and d). Similarly, the fibrotic scores in PM patients significantly increased in comparison with the healthy controls $(P<0.01$, Figure 1b). To further demonstrate the fibrosis degree of lung, we measured the collagen deposition using Masson staining. In parallel with the fibrosis scores, collagen deposition increased in patients compared with healthy groups $(P<0.01$, Figure 1c). These results demonstrate the features of ILD pathological changes in PM/DM.

\section{CB is Upregulated in Lung Tissues of PM/DM Patients}

We have recently reported that $\mathrm{CB}$ protein increases in muscle tissues of patients with PM. ${ }^{16}$ In this study, we analyzed the CB-positive cells in lung tissues from PM patients and healthy controls. Positive signals (Brown granules) were

Figure $3 \mathrm{HE}$, Masson's trichrome staining analyses of lung tissues and western blotting analysis, Immunohistochemical staining analysis of the expression of CB protein levels in lung tissues in a guinea-pig model of PM $(10 \times 40, n=6-8)$. Data are means \pm s.d. F1 $=$ sham group, F2 $=$ CVB + None group, $\mathrm{F} 3=\mathrm{CVB}+$ Saline group, $\mathrm{F} 4=\mathrm{CVB}+\mathrm{CA}-074 \mathrm{Me}$ group (f: upper panel). Infiltration of many inflammatory cells in lung tissues and fiber breakages were found in the CVB + None group and decreased in the CVB + CA-074Me group (a). The inflammatory score increased in the CVB + None group in comparison with the sham group, and decreased in the CVB + CA-074Me group with significant difference (b). The test of homogeneity of variance showed $P>0.1$, ANOVA test was applied. The histological lesion (the fibrosis score) increased significantly in the CVB + None group in comparison with the sham group, and decreased in the CVB + CA-074Me group (c). The test of homogeneity of variance showed $P<0.1$, nonparametric test was applied. The collagen area in lung tissues increased in the CVB + None group in comparison with the sham group, and decreased in the CVB + CA074Me group with significant difference (d). The test of homogeneity of variance showed $P>0.1, A N O V A$ test was applied. The expression of $C B$ protein levels was done by western blotting analysis in different groups, the prominent band at the molecular size of $\sim 27 \mathrm{kDa}$ represented the singlechain form of CB (e: upper panel); The gray scale value of CB in different groups was analyzed (e: lower panel). The test of homogeneity of variance showed $P<0.1$, nonparametric test was applied. Lung tissues containing yellow granulation (arrow showing) in the endochylema or nucleus were considered as positive. The test of homogeneity of variance showed $P<0.1$, nonparametric test was applied. The number of CB-positive cells increased in the CVB + None group in comparison with the sham group, and decreased in the CVB + CA-074Me group with significant difference (f: lower panel). ${ }^{*} P<0.05$ in comparison with the sham group, ${ }^{\#} P<0.05$ in comparison with CVB + CA-074Me group. 
a
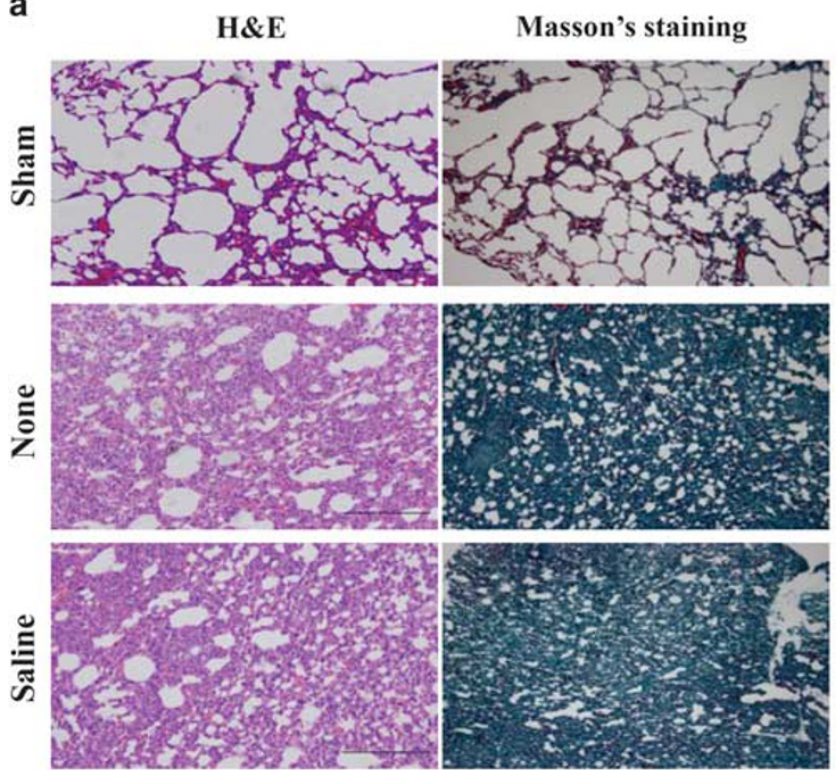

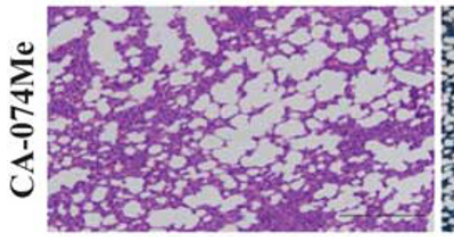

e

Sham None Saline CA-074Me
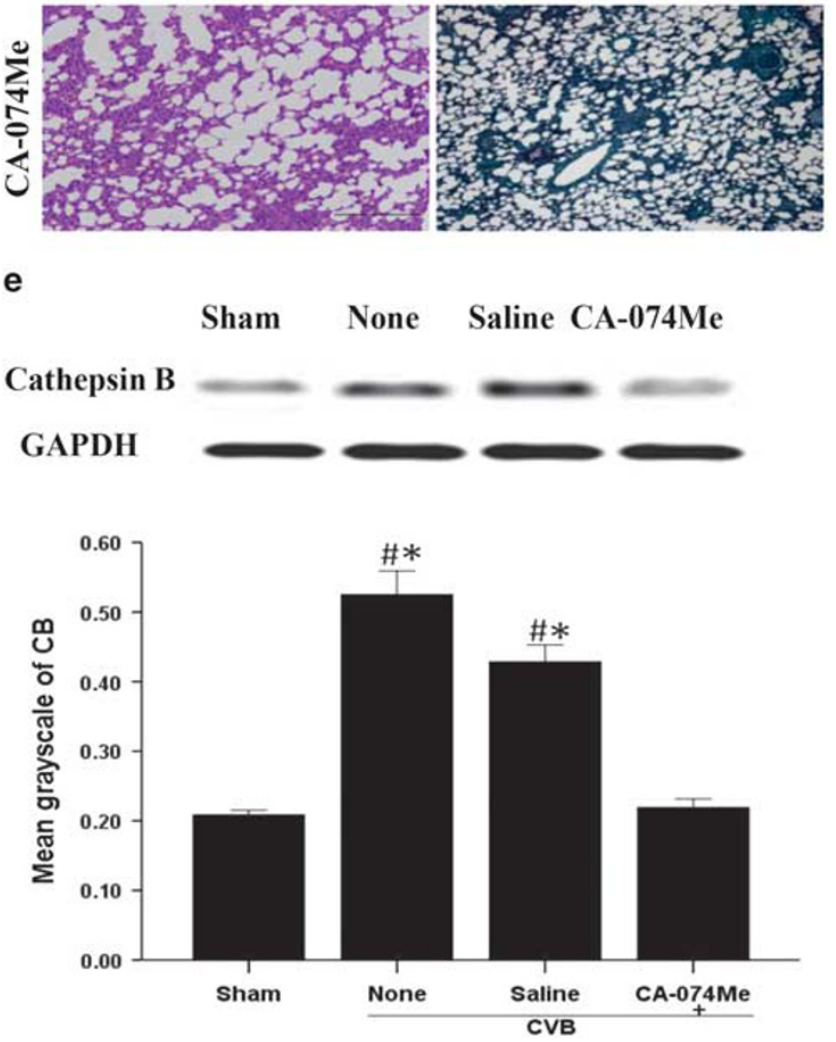
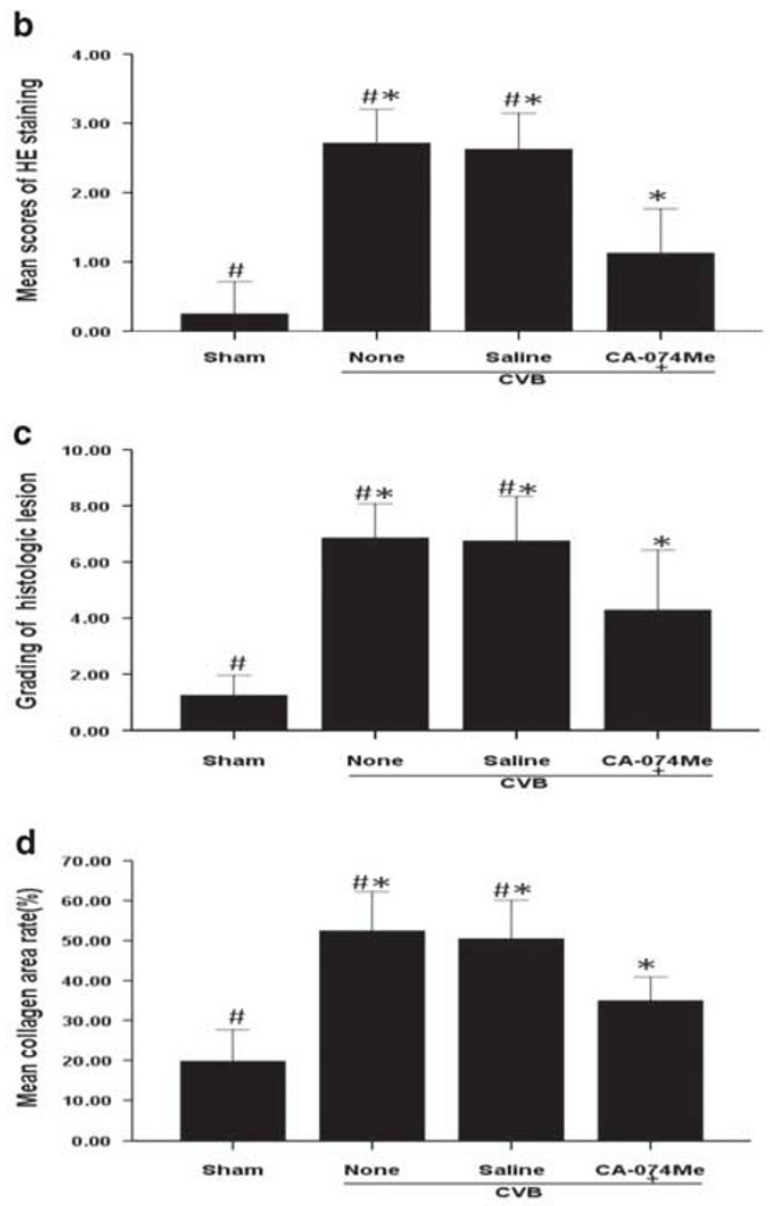

f
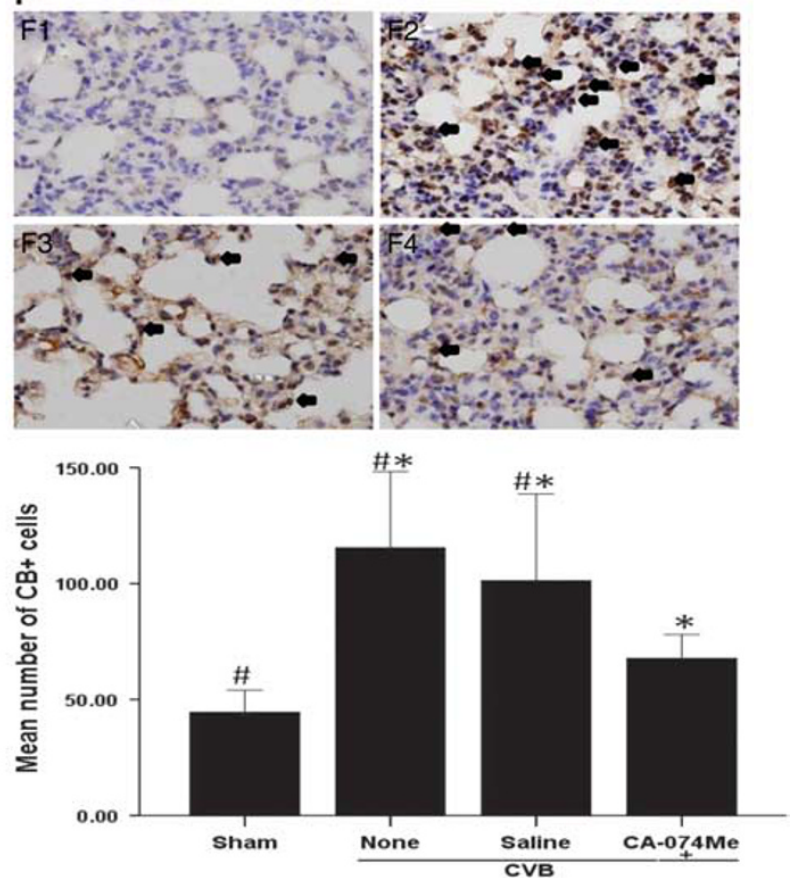
found mainly in cytoplasm of the lung tissues from PM/DM patients, but little in healthy controls (Figures $2 \mathrm{e}-\mathrm{A}, \mathrm{B}$ ). The number of CB-positive cells was significantly greater in $\mathrm{PM} / \mathrm{DM}$ patients than that in the healthy controls $(P<0.01$, Figure 2e). This result suggests that $\mathrm{CB}$ was upregulated in the lung tissues from PM/DM patients.

\section{CB Expression is Increased in the Lung Tissue in a Guinea Pig Model of PM}

We have recently established a chronic inflammatory polymyositis model in guinea pig induced by CVB1. ${ }^{16}$ To investigate the role of $\mathrm{CB}$ in the development of $\mathrm{PM}$, we measured the expression of $\mathrm{CB}$ in lung tissues from the guinea-pig model of PM induced by CVB1. Western blot analysis revealed that $\mathrm{CB}$ protein levels were significantly increased in $\mathrm{CVB}+$ None and $\mathrm{CVB}+$ Saline groups compared with the sham group $(P<0.01, P<0.01$, respectively; Figure 3e). Immunohistochemical analysis confirmed an increased number of CB-positive cells in the CVB + None and $\mathrm{CVB}+$ Saline groups compared with sham group $(P<0.01, P<0.01$, respectively; Figure $3 \mathrm{f})$. These results recapitulate the up-regulation of $\mathrm{CB}$ in guinea-pig model of PM induced by CVB1. Similar to PM patients, upregulation of $\mathrm{CB}$ correlated with inflammation and fibrosis in lung tissues of the guinea-pig model of CVB1-induced polymyositis (inflammatory score: $P<0.01$, Fibrosis score: $P<0.01$, Collagen area: $P<0.01$, respectively, Figures $3 \mathrm{a}-\mathrm{d}$; CD68 ${ }^{+}$cells: $P<0.01, \mathrm{CD}^{+}{ }^{+} \mathrm{T}$ cells: $P<0.01, \mathrm{CD} 4^{+} \mathrm{T}$ cells: $P>0.05$, respectively, Figures $4 \mathrm{a}-\mathrm{c}$ ).

\section{Inhibition of CB with CA-074Me Decreases Inflammation and Fibrosis in Lung Tissue from PM}

Although CB has been suggested to be associated with PM, it has never been demonstrated whether inhibition of $\mathrm{CB}$ would provide a therapeutic effect in PM. To address this, we used CA-074Me, a selective inhibitor of $\mathrm{CB}$, to inhibit $\mathrm{CB}$ in the guinea-pig model of CVB1-induced polymyositis. One animal died after CVB1 injection; however, no death and other health-related problems were observed in animals receiving $\mathrm{CA}-074 \mathrm{Me}$. In the $\mathrm{CVB}+\mathrm{CA}-074 \mathrm{Me}$ group, the scores of inflammation significantly decreased in comparison with the CVB + None group $(P<0.01$, Figure $3 b)$. This result demonstrates that inhibition of $\mathrm{CB}$ reduces inflammation and fibrosis in PM. Immunohistochemical analysis confirmed that in CVB $+\mathrm{CA}-074 \mathrm{Me}$ group, the number of $\mathrm{CD} 8^{+}$cells significantly decreased in comparison with the CVB group $(P<0.01$, Figure $4 \mathrm{a})$. The number of $\mathrm{CD} 8^{+} \mathrm{T}$ cells increased in the CVB + None compared with the sham group. In $\mathrm{CVB}+\mathrm{CA}-074 \mathrm{Me}$ group, the number of $\mathrm{CD} 8{ }^{+} \mathrm{T}$ cells decreased in comparison with the sham group $(P<0.01$, Figure 4b). However, this effect of CA-074Me seemed not to be associated with $\mathrm{CD} 4^{+} \mathrm{T}$ cells as the number of $\mathrm{CD} 4{ }^{+} \mathrm{T}$ cells were similar between CA-074Me treatment and other non-treated groups $(P>0.05$, Figure 4c). Similarly, the number of TNF- $\alpha$ - and TGF- $\beta 1$-positive cells were significantly increased in CVB group compared with the sham group $(P<0.01, P<0.01$, respectively, Figures $5 \mathrm{~d}$ and $\mathrm{e})$. In the CVB $+\mathrm{CA}-074 \mathrm{Me}$ group, the number of TNF- $\alpha$ - and TGF- $\beta 1$-positive cells significantly decreased in comparison with the CVB + None group $(P<0.01, P<0.01$, respectively, Figures $5 \mathrm{~d}$ and e). Western blot analysis confirmed that TNF$\alpha$ and TGF- $\beta 1$ were significantly increased in CVB + None group compared with the sham group $(P<0.01, P<0.01$, respectively, Figures $5 \mathrm{~b}$ and c). In the $\mathrm{CVB}+\mathrm{CA}-074 \mathrm{Me}$ group, the protein levels of TNF- $\alpha$ and TGF- $\beta 1$ significantly decreased in comparison with the CVB group $(P<0.01$, $P<0.01$, respectively, Figures $5 \mathrm{~b}$ and $\mathrm{c}$ ). To further demonstrate the fibrosis degree of the lung, we measured the collagen deposition using Masson staining. The alterations of collagen deposition correlated with the fibrosis scores $(P<0.05$, Figures $3 c$ and $d)$. This result demonstrates that inhibition of $\mathrm{CB}$ reduces fibrosis in PM.

\section{CA-074Me Attenuates Cell Apoptosis}

Apoptosis contributes to the loss of lung epithelial cells in PM. CB has been implicated in apoptosis. Thus, we hypothesized that inhibition of $\mathrm{CB}$ might prevent lung epithelial cell apoptosis in PM. To test this hypothesis, we detected apoptosis in lung tissues by TUNEL staining. The number of TUNEL-positive cells was significantly increased in CVB + None group compared with sham group $(P<0.05$, $P<0.05$ vs $\mathrm{CVB}+$ None group and CVB + Saline group, respectively, Figure 4d). However, administration of CA-074Me reduced apoptosis induced by CVB1 $(P<0.05$, Figure $4 \mathrm{~d}$ ). This result supports the view that $\mathrm{CB}$ has an important role in lung epithelial apoptosis in PM.

Figure 4 Immunohistochemical staining analysis of $C D 68, C D 8, C D 4$, and TUNEL assay $(10 \times 40, n=6-8)$. Data are means \pm s.d. $A 1$, B1, C1, D1 = sham group; A2, B2, C2, D2 = CVB + None group; A3, B3, C3, D3 = CVB + Saline group; A4, B4, C4, D4 = CVB + CA-074Me group (a-d: left panel). Infiltration of inflammatory cells in lung tissues were found in the CVB + None group and decreased in the CVB + CA-074Me group. The number of CD68 ${ }^{+}$cells, $\mathrm{CD}^{+}{ }^{+} \mathrm{T}$ cells, CD4 ${ }^{+} \mathrm{T}$ cells (yellow granulation, arrow showing cytoplasm and membrane localization) and TUNEL-positive cells (yellow-brown signal, arrow showing cytoplasm and nuclear localization) were quantitated. Both the number of $\mathrm{CD}_{6}{ }^{+}$cells and CD8 $+\mathrm{T}$ cells increased in the CVB + None group in comparison with the sham group, and decreased in the CVB + CA-074Me group with significant difference The test of homogeneity of variance showed $P>0.1$, nonparametric test was applied. (a, b: right panel).The numbers of $C D 4^{+} \mathrm{T}$ cells were similar among four groups (c: right panel). The test of homogeneity of variance showed $P<0.1$, nonparametric test was applied. Apoptotic rate increased in the CVB + None, CVB + Saline, and CVB + CA-074Me groups in comparison with the sham group. In CA-074Me group, the number decreased in comparison with CVB + None group with significant difference. The test of homogeneity of variance showed $P<0.1$, nonparametric test was applied (d: right panel). ${ }^{*} P<0.05$ in comparison with the sham group, ${ }^{\#} P<0.05$ in comparison with CA-074Me group. 
a

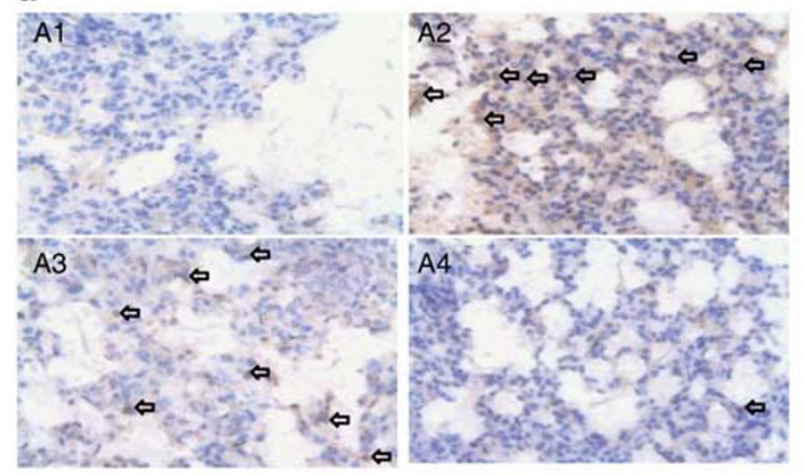

\section{b}
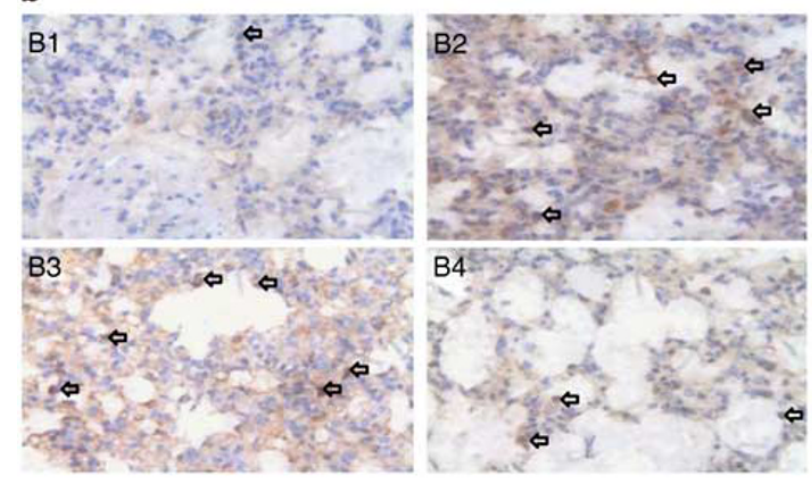

\section{$c$}
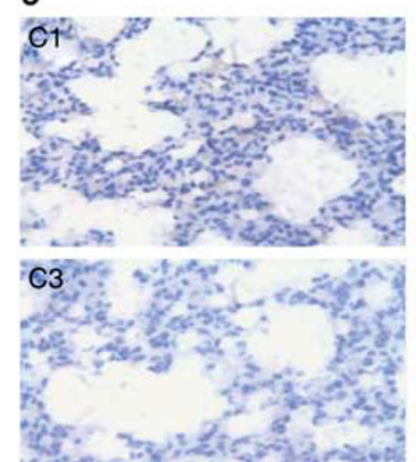

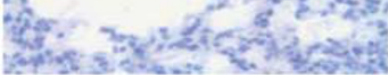

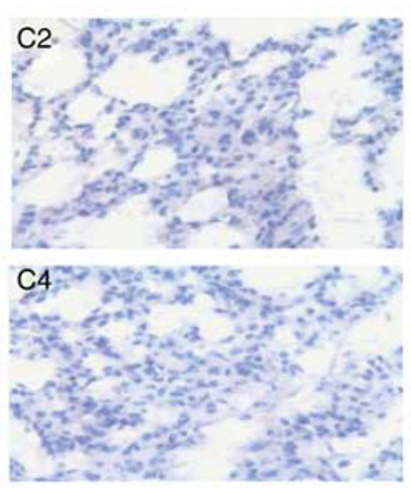

d
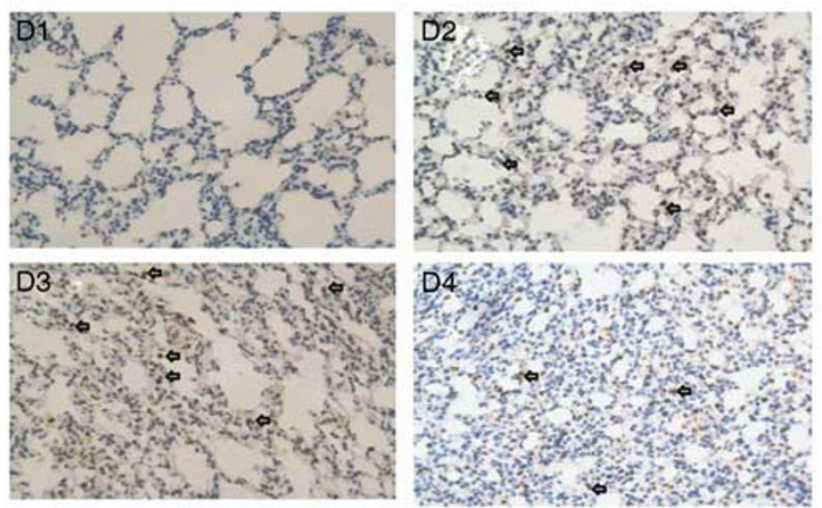
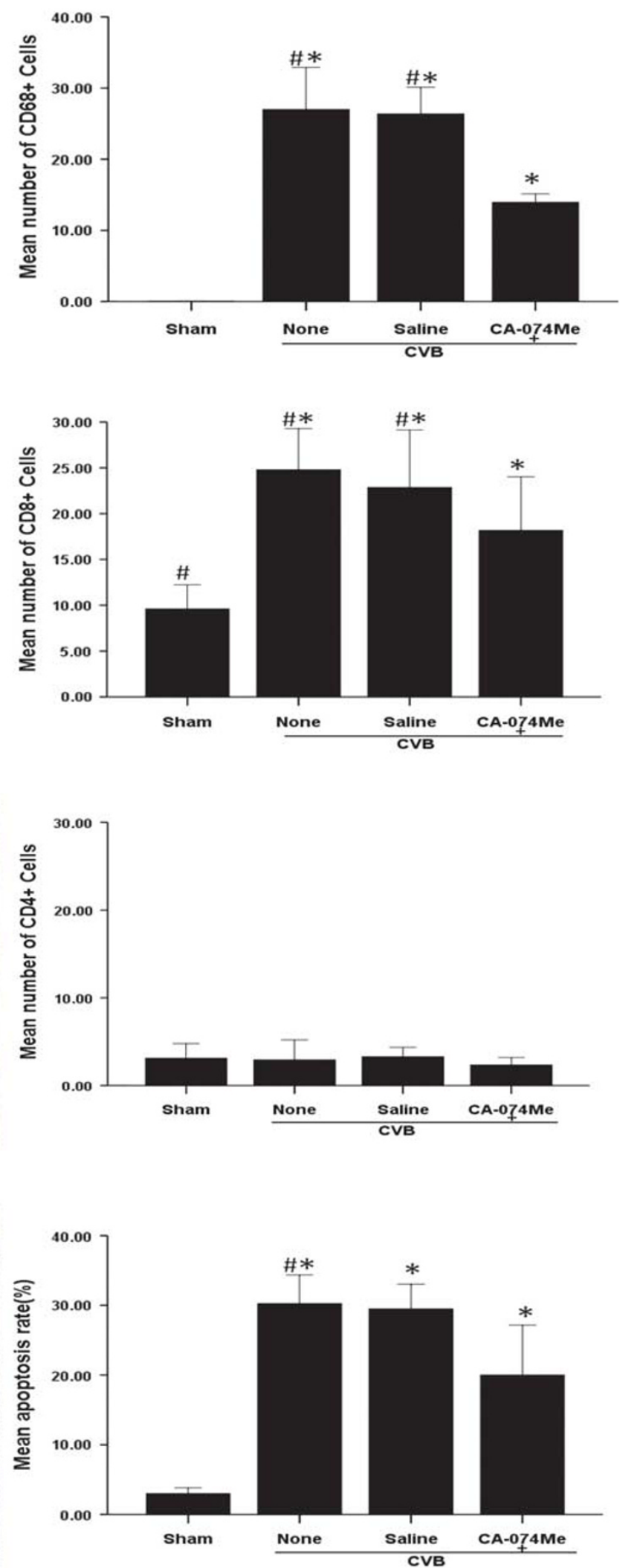
a

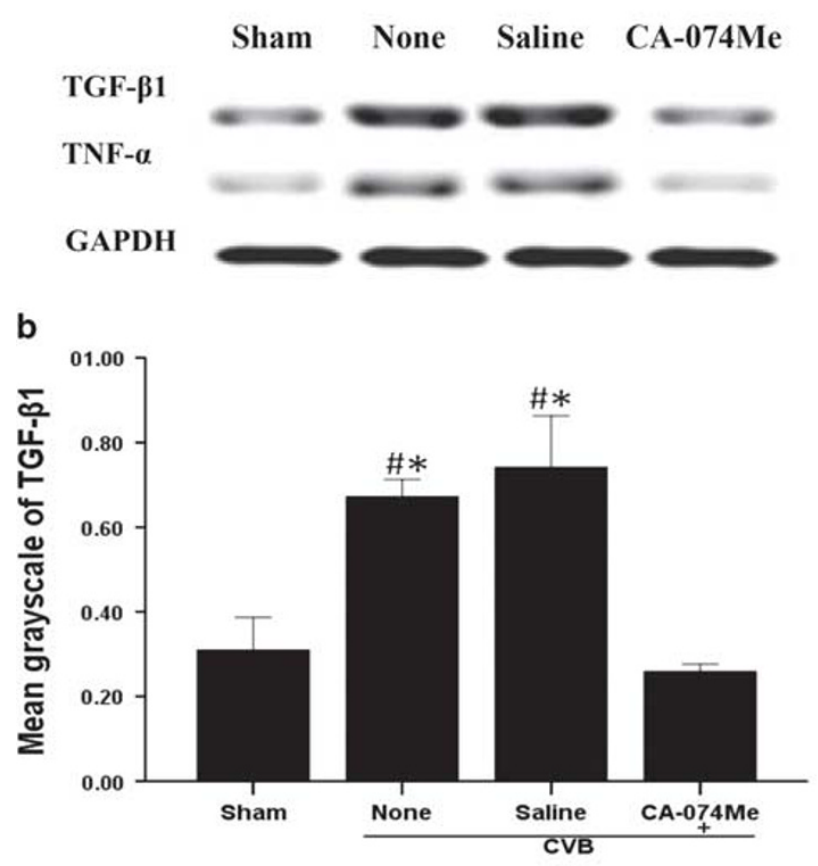

c

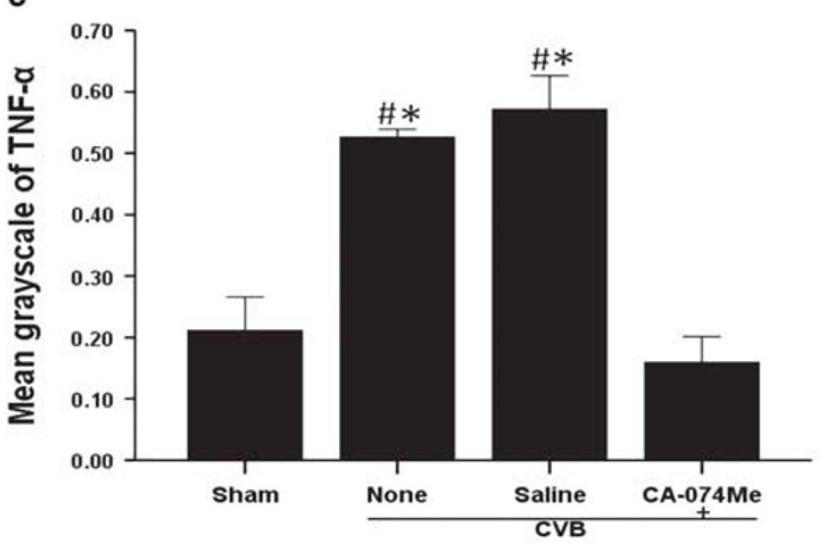

d
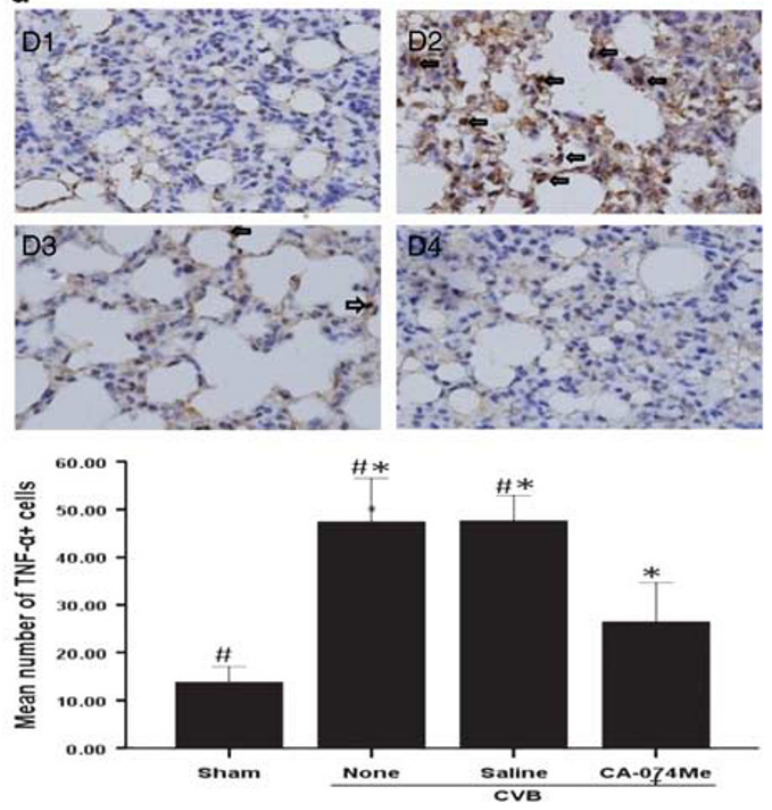

e
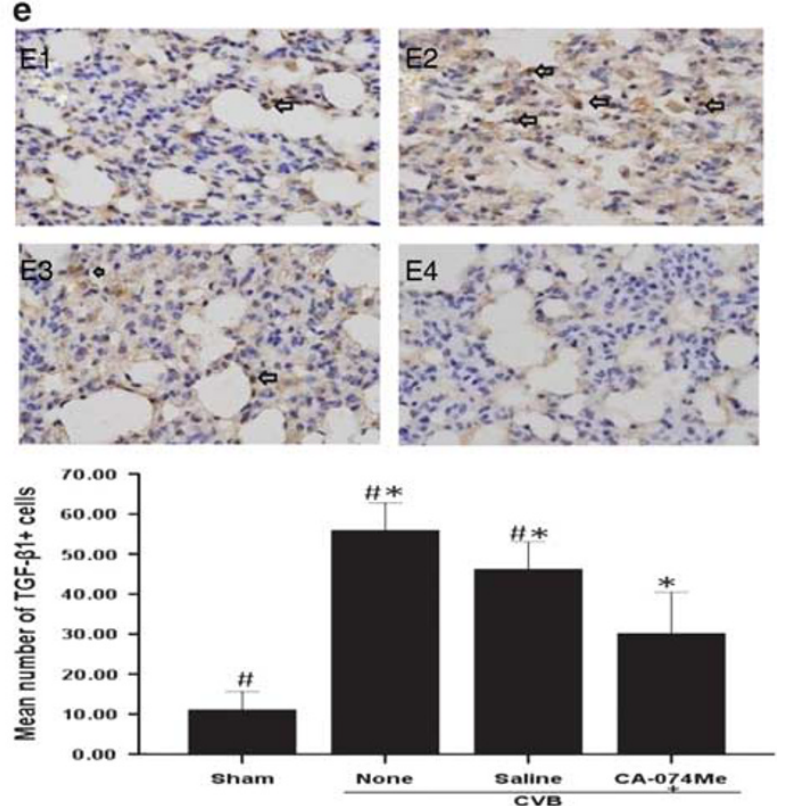

Figure 5 Western blotting analysis and Immunohistochemical staining analysis of TNF- $\alpha$ and TGF- $\beta 1$ assay $(10 \times 40, n=6-8)$. Data are means \pm s.d. D1, $\mathrm{E} 1$ = sham group; D2, E2 = CVB + None group; D3, E3 =CVB + Saline group; D4, E4 =CVB + CA-074Me group (d, e: left panel). The TGF- $\beta 1$ and TNF- $\alpha$ protein in different groups were done by western blotting analysis (a). The gray scale level of TGF- $\beta 1$ was much greater in the CVB group versus sham group with significant difference and significantly decreased in CVB + CA-074Me group in comparison with NS group and CVB group (b). The test of homogeneity of variance showed $P<0.1$, nonparametric test was applied. The gray scale level of TNF- $\alpha$ was much greater in the CVB + None group versus sham group with significant difference and significantly decreased in CVB + CA-074Me group in comparison with CVB + Saline group and CVB + None group (c). The test of homogeneity of variance showed $P>0.1$, AVONA test was applied. TNF- $\alpha$-positive cells, TGF- $\beta 1$-positive cells (yellow granulation, arrow showing cytoplasm and nuclear localization) were quantitated. Both the number of TNF- $\alpha$-positive cells and TGF- $\beta 1$-positive cells increased in the CVB + None, CVB + Saline, and CVB + CA-074Me groups in comparison with the sham group, and the number decreased in the CVB + CA-074Me group compared with CVB + None and CVB + Saline groups with significant difference. The test of homogeneity of variance showed $P>0.1$, AVONA test was applied (d, e: lower panel). ${ }^{*} P<0.05$ in comparison with the sham group, ${ }^{\#} P<0.05$ in comparison with CVB + CA-074Me group. 


\section{DISCUSSION}

We show here for the first time that the specific CB inhibitor CA-074Me decreased inflammation and fibrosis, and attenuated apoptosis in lung tissues in a guinea-pig model of CVB1-induced PM. CA-074Me downregulated TGF- $\beta 1$ induced fibrosis and macrophage-induced inflammation. Thus, our study suggests that $\mathrm{CB}$ may be the potential therapeutic target for ILD-PM.

The present study demonstrated that $\mathrm{CB}$ expression was upregulated in lung tissues both in PM patient and a guineapig model of CVB1-induced PM. Activation of CB has been implicated in fibrosis in ILD under various stresses. ${ }^{23,24}$ As $\mathrm{CB}$ has also been involved in the turnover/degradation of ECM, lysosomal cysteine proteases could also have a role in the development of lung fibrosis. ${ }^{25}$ And fibroblasts are regarded as the major cell type that mediates the onset and progression of lung fibrosis by secreting large amounts of ECM proteins. In addition, some insights of understanding the course of pulmonary fibrosis have come from greater number of $\mathrm{CD}^{+}{ }^{+}$cytotoxic $\mathrm{T}$ cells ${ }^{5}$ and $\mathrm{CD} 8^{+}$macrophages. ${ }^{6}$ Moreover, alternatively activated macrophages appear to be key players in pathologic processes that are associated with fibrosis. They are activated by profibrotic factors (TGF- $\beta$, IL- 4 ) produce profibrotic factors (TGF- $\beta$, monocyte chemotactic protein-1 (MCP-1)), and activate profibrotic T cells (type $2 \mathrm{~T}$ cells producing IL-4). ${ }^{26}$ Through autocrine TGF- $\beta$ the CC chemokine MCP-1 upregulated the production of collagen. ${ }^{27}$ In addition, the overexpression of type I collagen by systemic sclerosis fibroblasts is known to be TGF- $\beta$-dependent even though the cells do not produce elevated levels of active or latent TGF- $\beta 1{ }^{28}$ TGF- $\beta 1$ links inflammation to fibrogenesis and is one of the key mediators in the fibrotic process. ${ }^{29-32}$ It has been observed that integrin$\beta 6$ knockout mice develop lung inflammation but not pulmonary fibrosis after bleomycin exposure because of the absence of activation of latent TGF- $\beta$ by integrin- $\beta 6{ }^{33}$ As a downstream mediator of TGF- $\beta 1$, connective tissue growth factor has a crucial role in TGF- $\beta$-induced connective tissue cell proliferation and organic ECM deposition. ${ }^{34}$ And in an experimental cell model of differentiated fibroblasts (human lung CCD-19Lu cells), CB participated in lung fibroblast differentiation by triggering TGF- $\beta 1 /$ Smad pathway. ${ }^{35}$ However, the role of CB has not been completely clarified in PM-ILD. The present study provides direct evidence that $\mathrm{CB}$ activity is associated with fibrosis in ILD-PM and correlates with disease severity. We further show that $\mathrm{CB}$ stimulates TGF- $\beta 1$ expression, which is in line with the grade of fibrosis. Similarly, $\mathrm{CD}^{+} \mathrm{T}$ cells and $\mathrm{CD} 68+$ macrophages are elevated in ILD-PM. Previous studies have revealed that PM is characterized by $\mathrm{CD} 8+\mathrm{T}$-cell-mediated cytotoxicity against the major histocompatibility complex class I expressed by muscle fibers. In contrast to DM, CD4 $+\mathrm{T}$ cells and B cells are known to predominate in the perivascular areas of the muscle tissue. ${ }^{36}$ Nevertheless, there remains much about pathogenesis to be learned in ILD in PM/DM, which might differ from mechanisms in the lung. A recent study showed low counts of peripheral $\mathrm{T}$ cells and a low percentage of $\mathrm{CD} 4+\mathrm{T}$ cells were associated with the presence of ILD in PM/DM. ${ }^{37}$ Activated $\mathrm{T}$ cells, especially CD8 $+\mathrm{T}$ cells, are proven to have essential roles in ILD in PM/DM patients. ${ }^{38}$ In the presence of ILD, bronchoalveolar lavages consistently revealed lymphocytosis with a marked predominance of CD8 $+\mathrm{T}$ cells, which was associated with anti-Jo-1 autoantibodies. ${ }^{39}$ Recently, CX3CL1 and its receptor CX3CR1 might contribute to the inflammatory cell infiltration into the affected muscle and lung with ILD in PM/DM patients, among which CX3CR1 was expressed on a majority of CD8 $+\mathrm{T}$ cells, most macrophages, and some $\mathrm{CD} 4+\mathrm{T}$ cells in the lung. ${ }^{40}$ In our study, $\mathrm{CD} 8^{+} \mathrm{T}$ cell, $\mathrm{CD}^{+} 8^{+}$cell infiltrations were significantly increased in lung tissues in both $\mathrm{PM}$ and $\mathrm{DM}$, further confirms that PM and DM have similar mechanisms in the lung.

Previous study has demonstrated that human cysteine cathepsins are implicated in lung injuries and have recently emerged as important players in pulmonary inflammations, among which $\mathrm{CB}$ could display immunomodulatory functions by inactivating key proteins involved in the innate immunity defense. ${ }^{41}$ This is indeed supported by our study, which demonstrates the upregulation of $\mathrm{CB}$ in ILD-PM (Figures 2 and 3). As a ubiquitous endopeptidase and ectodipeptidase, $\mathrm{CB}$ has a clear association with neutrophils and several inflammation markers especially TNF- $\alpha .{ }^{42-44}$ Overexpression of TNF- $\alpha$ in the rat lungs led to severe pulmonary inflammation followed by accumulation of ECM, which was mediated by secondary upregulation of TGF- $\beta .^{45}$ TNF- $\alpha$ acts as a mediator of inflammation and cellular immune responses produced mainly by activated macrophages. ${ }^{46}$ Macrophages represent the predominant cell type, contributing to elevated CB levels, but other cell types also participate. ${ }^{41} \mathrm{CD} 8{ }^{+} \mathrm{T}$-cell responses are a critical arm of the immune response to respiratory virus infection and may have a role in the pathogenesis of ILD. The effect of TNF- $\alpha$ expressed by $\mathrm{CD}^{+} \mathrm{T}$ cells is mediated not exclusively by cytotoxicity, but also through the activation of alveolar target cells and their expression of inflammatory mediators. ${ }^{47}$ Our data show elevated levels of CB in ILD-PM, correlating with the increased numbers of $\mathrm{CD} 68^{+}$macrophages and $\mathrm{CD} 8{ }^{+} \mathrm{T}$ cells and elevated expression of TNF- $\alpha$.

TNF- $\alpha$-induced apoptosis is thought to involve mediators from acidic vesicles. CB has recently been implicated in apoptosis. These observations suggest that caspase-mediated release of $\mathrm{CB}$ from lysosomes enhances mitochondrial release of cytochrome $\mathrm{C}$ and subsequent caspase activation in TNF- $\alpha$-treated hepatocytes. ${ }^{44}$ Our recent study has confirmed that the elevated expression of CB led to increased apoptosis in muscle tissues of PM. In this study, we demonstrated that the increased expression of TNF- $\alpha$ was in line with the release of CB in lung tissues of ILD-PM. These results suggest that $\mathrm{CB}$ activation of TNF- $\alpha$ signaling mediates pulmonary cell apoptosis. 
To define the role of $\mathrm{CB}$ in $\mathrm{PM}$, we used CA-074Me to block $\mathrm{CB}$ activity. Treatment of cells with membrane-permeable CA-074Me effectively abolished intracellular CB activity, which is implicated in the degradation of ECM. ${ }^{48} \mathrm{CA}-074 \mathrm{Me}$ conferred a protective effect in OA-induced cell apoptosis and reduced amyloid precursor protein accumulation and $\alpha$-spectrin cleavage in Alzheimer's disease. ${ }^{49}$ In previous study, specific CB inhibitor CA-074Me attenuated the expression of $\mathrm{CB}$ in the development of ischemic astrocytic cell death both in in vivo and in vitro ischemic models. ${ }^{50}$ In liver fibrogenesis, $\mathrm{CB}$ also has an important role. And using $\mathrm{CB}$ inhibitor $\mathrm{CA}-074 \mathrm{Me}$ reproduced the antagonism of acidic sphingomyelinase (ASMase) in preventing the fibrogenic properties of HSCs. Moreover, CB expression increased in HSC and paralleled the increase of $\alpha$-smooth muscle actin and TGF- $\beta$ in signaling pathways of apoptosis and liver fibrosis. ${ }^{51-53}$ Altogether, these findings support a critical role for cathepsins in HSC activation, suggesting that the antagonism of cathepsins in HSC may be of relevance for the treatment of liver fibrosis. However, there is no report about the treatment of CA-074Me in ILD-PM. Our results showed that CA-074Me downregulated the level of CB, which participated in the progression of fibrosis, inflammation, and cell apoptosis. Thus, our data suggest that administration of CA-074Me can reduce the severity of ILD in PM.

In summary, this study demonstrates that the levels of $\mathrm{CB}$ are elevated in ILD-PM, and correlate with objective measures of disease severity. This study also demonstrates the pathological role of CB in ILD. The expression of CB, inflammation and fibrosis, and cell apoptosis are elevated in both PM patients and animal model of CVB1-induced PM. Inhibition of $\mathrm{CB}$ with $\mathrm{CA}-074 \mathrm{Me}$ reduces apoptosis, inflammation, and fibrosis in PM. Furthermore, the antifibrotic effect of CB inhibition seems to be mediated through TGF- $\beta 1$ and its anti-inflammation is associated with macrophages in PM lung tissues. Although further research in this area is needed, our results position $\mathrm{CB}$ as potential therapeutic targets for the treatment of ILD-PM.

\section{ACKNOWLEDGMENTS}

This study was supported by the grant awarded to Dr Qiang Wang from the Natural Science Foundation of Shanghai, China (Grant No.: 08ZR1402800). The authors also thank all patients who participated in this study.

\section{DISCLOSURE/CONFLICT OF INTEREST}

The authors declare no conflict of interest.

1. Dalakas MC. Polymyositis, dermatomyositis and inclusion-body myositis. N Engl J Med 1991;325:1487-1498.

2. Fathi $M$, Vikgren J, Boijsen $M$, et al. Interstitial lung disease in polymyositis and dermatomyositis: longitudinal evaluation by pulmonary function and radiology. Arthritis Rheum 2008;59:677-685.

3. Steen VD, Medsger TA. Changes in causes of death in systemic sclerosis, 1972-2002. Ann Rheum Dis 2007;66:940-944.

4. Walter N, Collard HR, King Jr TE. Current perspectives on the treatment of idiopathic pulmonary fibrosis. Proc Am Thorac Soc 2006;3:330-338.
5. Nuovo GJ, Hagood JS, Magro CM, et al. The distribution of immunomodulatory cells in the lungs of patients with idiopathic pulmonary fibrosis. Modern Pathol 2011;25:416-433.

6. Yamashita $M$, Iwama N, Date $F$, et al. Macrophages participate in lymphangiogenesis in idiopathic diffuse alveolar damage through CCL19-CCR7 signal. Hum Pathol 2009;40:1553-1563.

7. Corsini E, Giani A, Peano S, et al. Resistance to silica-induced lung fibrosis in senescent rats: role of alveolar macrophages and tumor necrosis factor- $\alpha$ (TNF). Mech Ageing Dev 2004;125:145-146.

8. Panopoulos ST, Sfikakis PP. Biological treatments and connective tissue disease associated interstitial lung disease. Curr Opin Pulm Med 2011;17:362-367.

9. Keir GJ, Maher TM, Ming $D$, et al. Rituximab in severe, treatmentrefractory interstitial lung disease. Respirology 2014;19:353-359.

10. Sfikakis PP. The first decade of biologic TNF antagonists in clinical practice: lessons learned, unresolved issues and future directions. Curr Dir Autoimmun 2010;11:180-210.

11. Uchiyama Y. Autophagic cell death and its execution by lysosomal cathepsins. Arch Histol Cytol 2001;64:233-246.

12. Yang CN, Shiao YJ, Shie FS, et al. Mechanism mediating oligomeric Abeta clearance by naïve primary microglia. Neurobiol Dis 2011;42:221-230.

13. Rempel SA, Rosenblum ML, Mikkelsen T, et al. Cathepsin B expression and localization in glioma progression and invasion. Cancer Res 1994;54:6027-6031.

14. Krepela E, Kasafirek E, Novak K, et al. Increased cathepsin B activity in human lung tumors. Neoplasma 1990;37:61-70.

15. Sinha AA, Morgan JL, Buus RJ, et al. Cathepsin B expression is similar in African-American and Caucasian prostate cancer patients. Anticancer Res 2007:27:3135-3141.

16. Feng $\mathrm{Y}, \mathrm{Ni} \mathrm{L}$, Wang $\mathrm{Q}$. Administration of cathepsin $\mathrm{B}$ inhibitor CA-074Me reduces inflammation and apoptosis in polymyositis. J Dermatol Sci 2013;72:158-167.

17. Lutgens SP, Cleutjens KB, Daemen MJ, et al. Cathepsin cysteine proteases in cardiovascular disease. FASEB J 2007;21:3029-3041.

18. Yan BZ, Wang M, Chen LY, et al. Role of cathepsin B-mediated apoptosis in fulminant hepatic failure in mice. World J Gastroenterol 2009:15:1231-1236.

19. Bohan A, Peter JB. Polymyositis and dermatomyositis (first of two parts). N Engl J Med 1975;292:344-347.

20. Bohan A, Peter JB. Polymyositis and dermatomyositis (second of two parts). N Engl J Med 1975;292:403-407.

21. Szapiel SV, Elsen NA, Fulmer JD, et al. Bleomycin-induced interstitial pulmonary disease in the nude, athymic mouse. Am Rev Respir Dis 1979:120:893-899.

22. Ashcroft T, Simpson JD, Timbrelli V. Simple method of estimating severity of pulmonary fibrosis on a numerical scale. J Clin Pathol 1988;41:467-470.

23. Hornung $V$, Bauernfeind $F$, Halle $A$, et al. Silica crystals and aluminum salts activate the NALP3 inflammasome through phagosomal destabilization. Nat Immunol 2008;9:847-856.

24. Altiok O, Yasumatsu R, Bingol-Karakoc G, et al. Imbalance between cysteine proteases and inhibitors in a Baboon model of bronchopulmonary dysplasia. Am J Respir Crit Care Med 2006;173:318-326.

25. Everts V, VanderZee E, Creemers L, et al. Phagocytosis and intracellular digestion of collagen, its role in turnover and remodelling. Histochem J 1996;28:229-245.

26. Atamas SP, White B. Cytokine regulation of pulmonary fibrosis in scleroderma. Cytokine Growth Factor Rev 2003;14:537-550.

27. Gharaee-Kermani M, Denholm EM, Phan SH. Costimulation of fibroblast collagen and transforming growth factor beta1 gene expression by monocyte chemoattractant protein-1 via specific receptors. J Biol Chem 1996;271:17779-17784.

28. Ihn H. Autocrine TGF-beta signaling in the pathogenesis of systemic sclerosis. J Dermatol Sci 2008;49:103-113.

29. Bonniaud $P$, Margetts PJ, Ask K et al. TGF- $\beta$ and Smad3 signaling link inflammation to chronic fibrogenesis. J Immunol 2005;175:5390-5395.

30. Kelly $M$, Kolb $M$, Bonniaud $P$, et al. Re-evaluation of fibrogenic cytokines in lung fibrosis. Curr Pharm Des 2003;9:39-49.

31. Border WA, Noble NA. Transforming growth factor- $\beta$ in tissue fibrosis. N Engl J Med 1994;331:1286-1292.

32. Yong SJ, Adlakha A, Limper AH. Circulating transforming growth factor- beta (1): a potential marker of disease activity during idiopathic pulmonary fibrosis. Chest 2001;120:68S-70S. 
33. Munger JS, Huang $\mathrm{X}$, Kawakatsu $\mathrm{H}$, et al. The integrin alpha $v$ beta 6 binds and activates latent TGF beta 1: a mechanism for regulating pulmonary inflammation and fibrosis. Cell 1999;96:319-328.

34. Kothapalli D, Frazier KS, Welply A, et al. Transforming growth factor beta induces anchorage-independent growth of NRK fibroblasts via a connective tissue growth factor dependent signaling pathway. Cell Growth Differ 1997;8:61-68.

35. Kasabova M, Joulin-Giet $A$, Lecaille $F$, et al. Regulation of TGF- $\beta 1$ driven differentiation of human lung fibroblasts: emerging roles of cathepsin B and cystain C. J Biol Chem 2014;289:16239-16251.

36. Reed AM, Ernste $F$. The inflammatory milieu in idiopathic inflammatory myositis. Curr Rheumatol Rep 2009;11:295-301.

37. Wang DX, Lu X, Zu N, et al. Clinical significance of peripheral blood lymphocyte subsets in patients with polymyositis and dermatomyositis. Clin Rheumatol 2012;31:1691-1697.

38. Takada K, Nagasaka K, Miyasaka N. Polymyositis/dermatomyositis and interstitial lung disease: A new therapeutic approach with T-cellspecific immunosuppressants. Autoimmunity 2005:38:383-392.

39. Sauty A, Rochat $T$, Schoch OD, et al. Pulmonary fibrosis with predominant CD8 lymphocytic alveolitis and anti-Jo-1 antibodies. Eur Respir J 1997;10:2907-2912.

40. Suzuki F, Kubota T, Miyazaki Y, et al. Serum level of soluble CX3CL1/ fractalkine is elevated in patients with polymyositis and dermatomyositis, which is correlated with disease activity. Arthritis Res Ther 2012;14:R48.

41. Koslowski R, Knoch K, Kuhlisch E, et al. Cathepsins in bleomycininduced lung injury in rat. Eur Respir J 2003;22:427-435.

42. Martin SL, Moffitt KL, McDowell A, et al. Association of airway cathepsin B and $\mathrm{S}$ with inflammation in cystic fibrosis. Pediatr Pulm 2010;45:860-868.

43. Moffitt $\mathrm{KL}$, Martin $\mathrm{SL}$, Jones $\mathrm{AM}$, et al. Inflammatory and immunological biomarkers are not related to survival in adults with Cystic Fibrosis. J Cyst Fibros 2014;13:63-68.
44. Guicciardi ME, Deussing J, Miyoshi $\mathrm{H}$, et al. Cathepsin B contributes to TNF-alpha-mediated hepatocyte apoptosis by promoting mitochondrial release of cytochrome c. J Clin Invest 2000;106: 1127-1137.

45. Sime PJ, Marr RA, Gauldie D, et al. Transfer of tumor necrosis factoralpha to rat lung induces severe pulmonary inflammation and patchy interstitial fibrogenesis with induction of transforming growth factorbeta1 and myofibroblasts. Am J Pathol 1998;153:825-832.

46. Beutler B, Cerami A. Cachectin: more than a tumor necrosis factor. N Engl J Med 1987;316:379-385.

47. Zhao MQ, Stoler MH, Liu AN, et al. Alveolar epithelial cell chemokine expression triggered by antigen-specific cytolytic CD8(+) T cell recognition. J Clin Invest 2000;106:R49-R58.

48. Premzl A, Turk V, Kos J. Intracellular proteolytic activity of cathepsin B is associated with capillary-like tube formation by endothelial cells in vitro. J Cell Biochem 2006;97:1230-1240.

49. Cho K, Yoon SY, Choi JE, et al. CA-074Me, a cathepsin B inhibitor, decreases APP accumulation and protects primary rat cortical neurons treated with okadaic acid. Neurosci Lett 2013;548:222-227.

50. Xu M, Yang L, Rong JG, et al. Inhibition of cysteine cathepsin B and L activation in astrocytes contributes to neuroprotection against cerebral ischemia via blocking the tBid-mitochondrial apoptotic signaling pathway. Glia 2014;62:855-880.

51. Moles A, Tarrats N, Fernández-Checa JC, et al. Cathepsin B overexpression due to acid sphingomyelinase ablation promotes liver fibrosis in Niemann-Pick Disease. J Biol Chem 2012;287: 1178-1188.

52. Moles A, Tarrats N, Fernández-Checa JC, et al. Cathepsins B and D drive hepatic stellate cell proliferation and promote their fibrogenic potential. Hepatology 2009;49:1297-1307.

53. Moles A, Tarrats N, Morales A, et al. Acidic sphingomyelinase controls hepatic stellate cell activation and in vivo liver fibrogenesis. Am J Pathol 2010;177:1214-1224. 